\title{
A Universidade, o Fórum de Ciência e Técnica e o Desenvolvimento Local Sustentável em Cuba
}

\section{Introdução}

Quando da realização da tese doutoral sobre a contribuição da tecnologia social e da economia solidária para o desenvolvimento local, surgiu a seguinte questão: se no campo capitalista, mais especificamente no Brasil, encontramos vários adjetivos para tecnologia, tais como social, capitalista, convencional, apropriada, branda e muitos outros, é possível falarmos em tecnologia socialista? Visando encontrar resposta fomos à Cuba.

$\mathrm{O}$ artigo que aqui se apresenta resulta de entrevistas realizadas com profissionais cubanos, dentre eles professores universitários com destaque para Jorge Nuñes Jover, Coordenador do Programa de Gestión Universitaria del Conocimiento y la Innovación para el Desarrollo (GUCID); Sergio Guerra Vilaboy, Presidente da Asociación de Historiadores Latinoamericanos y del Caribe (ADHLAC) e Carlos Cesar Torres Paes, Director del Centro de Estudios de Gerencia, Desarrollo Local y Turismo e Presidente Nacional de la Sociedad Cubana de Desarrollo Local; os periodistas Pedro Martínez Pírez, Subdirector de Radio Habana Cuba e Enrique Ubieta Gómes, diretor da Revista Cuba Socialista; Manuel Limonta,

\footnotetext{
${ }^{1}$ Graduação em Economia (Universidade Regional de Blumenau, 1983), Mestrado em Administração Pública (Universidade Federal de Santa Catarina, 1988) e Doutorado em Geografia Humana (Eberhard-Karls Universität Tübingen/Alemanha, 1997), com Pós-Doutorados em Política Científica e Tecnológica (Unicamp, 2008) e em Desenvolvimento Regional (Universidade de Santa Cruz do Sul, 2016). Professor titular da Universidade Regional de Blumenau desde 1986, com atuação no ensino de graduação (Economia) e pós-graduação (Desenvolvimento Regional). theis@furb.br

${ }^{2}$ Graduação em Ciências Sociais (Universidade Federal de santa Cataria, 1987), Mestrado em Sociologia Política (Universidade Federal de Santa Catarina, 1992) e Doutorado em Desenvolvimento Regional (Universidade Regional de Blumenau, 2019). Professor da Universidade Regional de Blumenau desde 2000. nelgarcia@furb.br
} 
Cientista criador do Centro de Biotecnologia de Cuba; Juan Luiz Martins, Coordenador do Polo de Humanidades, assim como Maria del Carmem Barroso González, Diretora do Departamento de Relações Internacionais da Asociación Nacional de Agricultores Pequeños (ANAP), além de membros de Cooperativas não agrícolas. Destas entrevistas, resultaram várias indicações bibliográficas, principalmente feitas por pensadores cubanos que versam sobre o desenvolvimento local e as contribuições oriundas da universidade e do Fórum de Ciência e Técnica.

Nosso objetivo consiste em apresentar fragmentos históricos que pensamos importantes para evidenciar a institucionalização e o desempenho da universidade com sua ciência, tecnologia e inovação e do Fórum de Ciência e Técnica na realização do desenvolvimento local sustentável cubano que vem sendo efetivado desde o início do século XXI.

Para apresentar os dados obtidos, o artigo está assim estruturado: seguidas à introdução, são apresentadas informações sobre a base teórica que sustenta a prática do desenvolvimento local cubano. Na sequência, são tecidas considerações sobre fragmentos históricos que explicitam o surgimento e o desenvolvimento de instituições científicas e tecnológicas a partir do governo revolucionário. No terceiro momento, apresenta-se aspectos relevantes sobre a universidade com sua ciência, tecnologia e inovação-no século XXI e que contribuem, efetivamente, na implantação do desenvolvimento local sustentável de Cuba. Encerra-se este item apresentando três casos exitosos da aproximação entre universidade e desenvolvimento local. No quarto item, centramos a atenção no Fórum de Ciência e Técnica que é uma particularidade do desenvolvimento cubano e que em muito contribui para inovação e solução dos seus problemas locais. Finalmente, apresenta-se as considerações finais. Cabe esclarecer que a opção feita para este artigo foi de apresentar informações sobre Cuba através de uma revisão histórica descritiva analítica, considerando que poucas ou distorcidas são as mensagens que nos chegam através dos meios de comunicação tradicionais.

\section{Desenvolvimento Local Sustentável Cubano}

Desde o início do século XXI, a situação econômica e social de Cuba passa por mudanças devido aos acordos de cooperação com a República Popular da China, com a República Bolivariana da Venezuela, com o Vietnã e, em menor escala, mas não menos 
importante, com as relações de exportação e importação com os Países Baixos, Canadá, Brasil, Espanha e, mais especificamente com os Estados Unidos, com quem em 2014 restabeleceu relações diplomáticas. Entretanto, ao chegar no final da primeira década deste novo século a situação volta a ficar preocupante devido as ações de restrição intensificadas pelo governo estadunidense.

Seguindo as pautas traçadas no VI Congresso do Partido Comunista (2011), Cuba tem apresentado dados positivos desde o último censo cubano, de 2012: 97,8\% das casas em Cuba, naquele ano, tinham acesso à eletricidade; a medicina era e continua sendo totalmente gratuita para toda a população; a mortalidade infantil estava baixa, se aproximando dos países desenvolvidos $(5,4 \%)$; a mortalidade geral estava em $7,1 \%$; a esperança de vida ao nascer era de 76 anos para os homens e 80 para as mulheres; e o analfabetismo, praticamente zero (Vilaboy, 2015). Atualmente esta situação está ameaçada diante das ações do governo estadunidense que volta a instituir sanções sobre Cuba atingindo, fundamentalmente, o abastecimento de petróleo, proporcionando crise energética, de abastecimento e no turismo.

Embora os dados de Cuba no século XXI tenham sido positivos, vide o IDH $(0,0778)$, por exemplo, que a coloca entre os dez melhores do mundo, o país continua a enfrentar sérias dificuldade, principalmente no que diz respeito aos baixos salários, à falta de soberania alimentar e à dependência de produtos industrializados. Segundo Pedro Martínez Pírez, em entrevista concedida em 14 de julho de 2017 ,

(...) a grande maioria dos trabalhadores cubanos têm seu salário insuficiente para poder enfrentar a realidade econômica de Cuba hoje. Embora tenhamos saúde e educação gratuitas, gás barato, água barata, eletricidade barata, habitação barata, os alimentos são caros e isso freia tudo, inclusive a produtividade do trabalho (Pírez, 2017).

Diante dos desafios atuais de Cuba, cuja origem está, fundamentalmente, no bloqueio imposto pelo governo estadunidense e na crise internacional do capitalismo, três alternativas são colocadas para Cuba: seguir no socialismo, mudar para o capitalismo ou construir uma nova alternativa. A partir das entrevistas realizadas em Havana e pelas leituras que de lá foram feitas, observamos que uma das formas pelas quais o governo cubano está tentando resolver o dilema é pela implantação de ações oriundas das propostas do desenvolvimento local sustentável, visando à construção de um novo tipo de socialismo cujo papel da universidade com sua ciência, tecnologia e inovação tem sido fundamental. 
Embora a idealização do Desenvolvimento Local Sustentável Cubano (DLSC) tenha iniciado ainda no período especial dos anos de 1990, ele passou a ser viabilizado, efetivamente, a partir de 2001, por inciativas do Ministério de Economia e Planificação, que começou a adotar um conjunto de ações intituladas Iniciativa Municipal de Desarrollo Local (IMDL), visando substituir importações e promover exportações, fundamentado na autosustentabilidade econômica (Días, 2014). A partir de 2010, a IDML foi estendida para todo o país com o financiamento do Fundo de Fomento, administrado pelo Banco de Crédito e Comércio, exceto Havana, cuja responsabilidade do desenvolvimento local está com o Banco Metropolitano. Outra instituição estatal que contribui na efetivação do desenvolvimento local é o Centro de Desarrollo Local (CEDEL), vinculado ao Ministério de Ciência, Tecnologia e Meio Ambiente, que realiza o Programa de Desarrollo Local (PRODEL), desenvolvendo um trabalho de conscientização e assessoria com as autoridades municipais (Díaz, 2014).

A proposta ganhou força a partir do VI Congresso do Partido Comunista Cubano, em 2011, quando medidas foram aprovadas para reforçar a autonomia dos municípios. Sua fundamentação está, sobretudo, na planificação como "herramienta fundamental para conducir el desarrollo económico del país a partir de activar los recursos endógenos existentes en las localidades: articulación de los intereses nacionales, ramales y territoriales en el contexto de la localidad" (Ceballos, 2011, p.192).

O DLSC se fundamenta no conceito de território, pois, ao se considerar a dimensão local/territorial nos processos de desenvolvimento, pode-se construir um processo que propõe

(...) a concertación y las alianzas de actores, en busca del mejoramiento de las condiciones de vida de la sociedad en esos ámbitos. Su formulación requiere tender fundamentalmente el conjunto de relaciones sociales, políticas, económicas institucionales, culturales y ambientales que actúan en el contexto territorial" (Segura; Lopes, 2011, p.12).

O território, nessa concepção, é entendido como um conjunto dinâmico, delimitado por uma fronteira, no qual se combinam os elementos ambientais e humanos; ele é o local onde se vive a heterogeneidade e a complexidade do mundo real. Nele, têm-se as características ambientais, os atores sociais e as mobilizações em torno de estratégias e projetos. Sua definição pode ser apresentada através de Segura (2013), ao dizer que, no caso cubano, quando se fala em desenvolvimento local, 
capacidad de los actores locales y de dirigir esos procesos en función de las necesidades propias, que en el caso cubano, además, está en correspondencia con los objetivos y prioridades de desarrollo local (Segura, 2013, p.142).

É importante se destacar que os defensores do DLSC têm a efetiva consciência de que o desenvolvimento local teve sua origem na Europa, em plena crise do capitalismo globalizado nos anos de 1980, e tinha como objetivo incrementar a capacidade empreendedora local, ou seja, ampliar a competitividade das cidades diante da crise. Além disso, sabem que o interesse do desenovlimento local era puramente desenvolver o local sob a égide do capitalismo, visando "acciones de capacitación de potenciales creadores de empresas, así como las políticas de formación de empleos mediante la cooperación entre los agentes públicos y privados, con el objetivo de generar capacidades económicas para la comunidad y región" (Alfonso, 2011, p.24).

No entanto, os teóricos cubanos defensores do desenvolvimento local, aqui representado por Alfonso (2011), Segura (2011, 2013), Gonzáles; Samper (2006), Vega (2012), Jover (2017, 2016, 2015), entre outros, entendem o local como o espaço para uma nova construção política, para uma concepção que viabiliza a conquista do desenvolvimento contraposta à natureza individualista e excludente do capital, uma política alternativa que proporciona a construção de uma sociedade superior à capitalista (Alfonso, 2011). Nessa perspectiva, se considera que

(...) la articulación práctica de la concepción del desarrollo local constituye, en los momentos actuales, un modelo de desarrollo socioeconómico imprescindible, necesario - en términos filosóficos - para la construcción de esta sociedad superior bajo cualquier condición: lo mismo a partir de una economía capitalista avanzada, como de una subdesarrollada (Alfonso, 2011, p. 29).

Em Cuba, a práxis do Desenvolvimento Local acontece nos territórios em nível provincial, municipal, microrregional e regional, e tem como atores o setor empresarial (estatal), a sociedade civil, o governo local, as instituições e os cidadãos. Mas, segundo a concepção de Díaz (2014), não se pode caracterizar como Desenvolvimento Local qualquer iniciativa. O DL efetivo é aquele capaz de promover o crescimento, modificar a estrutura econômica e gerar melhores condições de vida à população local. Além disso, a iniciativa

(...) deberá impulsar una mayor y mejor oferta de productos y servicios; un mejor acceso a la educación, la salud, los deportes y la cultura; y deberá hacer posible que el hombre pueda participar en el análisis de los problemas que más le afectan, en la toma de decisiones y en su apelación y control, en un ambiente de equidad social” (Díaz, 2014, p.192). 
De acordo com os Lineamientos de la política económica y social del Partido y la revolución para el período 2016-2021, aprovado no VII Congresso do PCC (2016), em que estão estabelecidas as pautas para a implantação de um conjunto de mudanças visando à atualização do modelo socialista cubano, tem-se:

(...) [cabe ao Estado] impulsar el desarrollo de los territorios a partir de la estrategia del país, de modo que se fortalezcan los municipios como instancia fundamental, con la autonomía necesaria, sustentables, con una sólida base económico-productiva, y se reduzcan las principales desproporciones entre estos, aprovechando sus potencialidades". (PCC, 2016, p.9).

Já o Lineamiento 35 do VI Congreso do Partido Comunista Cubano de 2011 diz que "Los Consejos de la Administración Provinciales y Municipales cumplirán funciones estatales y no intervendrán directamente en la gestión empresarial (PCC, 2011, p.7)”. No Lineamiento 37, por sua vez, está dito que

\begin{abstract}
El desarrollo de proyectos locales, conducidos por los Consejos de Administración Municipales, en especial los referidos a la producción de alimentos, constituye una estrategia de trabajo para el autoabastecimiento municipal, favoreciendo el desarrollo de las miniindustrias y centros de servicios, donde el principio de la autosustentabilidad financiera será el elemento esencial, armónicamente compatibilizado con los objetivos del plan de la Economía Nacional y de los municipios. Los proyectos locales una vez implementados serán gestionados por entidades económicas enclavadas en el municipio (PCC, 2011, p.8).
\end{abstract}

Assim, o Desenvolvimento Local em Cuba constitui uma complementação fundamental da política de desenvolvimento do país e se concretiza como uma política do Estado, pois, segundo Gonzáles; Samper (2006),

(...) las iniciativas de desarrollo local deben revitalizar el vínculo entre las autoridades centrales y la administración provincial y municipal, brindando mayor protagonismo a los actores locales en la búsqueda de soluciones a sus propios problemas, teniendo siempre en cuenta la correspondencia con dichos lineamientos nacionales (Gonzáles; Samper, 2006, s/p apud Pérez et al., 2016, p.100).

Com o que foi exposto até aqui, arriscamos a afirmar que o Desenvolvimento Local promovido em Cuba não se encaminha para a privatização dos recursos, nem está direcionado para a fragmentação dos setores populares, muito menos para o restabelecimento de estratégias visando à acumulação capitalista. Ele está sim embasado na ideologia da Revolução e nos princípios da "equidad, la justicia social, el acceso a la educación masiva de calidad. Un desarrollo donde se integran las escalas, nacional y provincial con el contexto municipal, en la búsqueda del mejoramiento de la calidad de vida de la población” (Vega et 
al., 2012, p.3). No socialismo cubano, a concepção teórica e o modelo do desenvolvimento local constituem uma ferramenta confiável para desenvolver as bases materiais, objetivas e subjetivas "de esta nueva sociedad; el contexto para estimular el funcionamiento del capital social y la realización económica de las diferentes formas de propiedad asociadas al sistema socialista de producción" (Alfonso, 2011, p.30).

O Desenvolvimento Local Sustentável Cubano pode ser entendido como o termo adequado para estimular valores e comportamentos econômicos, social, cultural e ambiental, que busca concretizar a propriedade socialista dos meios de produção (Alfonso, 2011) e, no seu processo de efetivação, a universidade juntamente com o Ministério de Educação Superior e centros de investigações vêm desempenhando importante papel, pois o Desenvolvimento Local demanda conhecimento, tecnologia e inovação, visando apresentar soluções criativas aos problemas sociais locais. A universidade, segundo Jorge Nuñes Jover, "tiene una potencialidad grande para fertilizar, impulsar la innovación, para impulsar la tecnología que ayudan a resolver problemas sociales de diferentes características” (Jover, 2017, s/p).

As relações que a universidade estabelece ao participar do Desenvolvimento Local em Cuba levam o Estado a implementar ações de ciência, de tecnologia e de inovação não só de ponta (high-tech), mas também voltadas para as necessidades da população. Nesse sentido, profissionais da universidade cubana pensam e agem para além das determinações do mercado. Para Joven e Quiñones (2016), por exemplo, as universidades “(...) pueden contribuir a incentivar la proyección local del conocimiento y la innovación, ampliando su capacidad de fomentar el bienestar humano en los territorios" (Joven; Quiñones, 2016, p. 195).

Para que se possa compreender a contribuição da universidade no desenvolvimento local cubano, passaremos, a partir de agora, a tecer considerações sobre os aspectos históricos relevantes na produção da ciência, da tecnologia e da inovação a partir do governo revolucionário.

\section{Fragmentos Históricos da Universidade com sua Ciência, Tecnologia e Inovação a partir do Governo Revolucionário}

Em Cuba, a produção da ciência, da tecnologia e da inovação está sob a responsabilidade do Estado e é realizada através de universidades, centros, institutos de 
pesquisas e Parques Tecnológicos, que foram desenvolvidos fundamentalmente a partir da implantação do governo revolucionário. Aqui, apresentaremos algumas ações do Estado cubano que consideramos relevantes para a compreensão do processo que fez com que Cuba seja o que é atualmente.

O marco da contribuição da universidade no processo de construção do socialismo cubano se deu em 15 de janeiro de 1960, quando Fidel Castro, no vigésimo aniversário da Sociedade Espeleológica disse “(...) el futuro de nuestra Patria tiene que ser necesariamente un futuro de hombres de ciencia, de hombres de pensamiento" (Castro, 1960, s/p apud Dávila, 2016, p. 157). Menos de dois meses após esse pronunciamento, em 2 de março, Che Guevara disse, em palestra (intitulada $O$ papel da universidade no desenvolvimento econômico de $C u b a$ ) na Universidade de Habana, "o que temos visto é a triste realidade de que a preparação que dão as universidades do país não é adequada nem em orientação nem em quantidade para as novas necessidades da Revolução" (Guevara, 1982, p. 161). Em sua perspectiva, as universidades não estavam proporcionando os técnicos necessários para o desenvolvimento socialista, seja em termos quantitativos, seja em termos qualitativos.

Em 1962, através da Lei no 1011 de 20 de fevereiro, foi criada a Comissão Nacional da Academia de Ciências de Cuba e realizada uma ampla reforma universitária com os seguintes objetivos: incorporar pesquisas científicas em todos os centros do ensino superior; criar escolas independentes de ciências básicas; iniciar o ensino da ciência teórica e aplicada através da criação do Centro Nacional de Investigações Científicas e criar a faculdade preparatória "obrero-campesina" (Díaz-Balart, 2002). Essa reforma, chamada por Jover e Quiñones (2016) de "giro a la investigación”, generalizou a investigação científica na vida universitária e permitiu capacitar atores que almejavam fazer da universidade um agente de mudança social. Além disso, a partir da reforma universitária, novos cursos foram criados, bem como o Centro de Pesquisa em Minas e Metalurgia e o Instituto Cubano de Pesquisa dos Derivados da Cana-de-açúcar. Em 1963, foram definidos, por Ernesto Che Guevara, os objetivos dos institutos de investigações, dos quais se destacam o Instituto Cubano de Investigação Tecnológicas e o Instituto Cubano para o Desenvolvimento de Maquinaria, cuja ação ficaria centrada na fabricação de peças de reposição para os equipamentos agrícolas (Viani, 1999).

Em julho de 1965, foi criado o Centro Nacional de Investigações Científicas (CENIC), voltado para pesquisas nos campos da química, bioquímica e biologia, como parte da 
estratégia de desenvolvimento definida pelo governo revolucionário. Segundo Guevara (1982), nesse momento teria início um processo de desenvolvimento que abarcaria seis ramos básicos da produção, a saber: “a química pesada, a química orgânica a partir dos hidrocarbonetos da cana de açúcar, a mineração, os combustíveis, a metalurgia em geral e particularmente a siderurgia, e os produtos derivados do nosso desenvolvimento agropecuário intensivo" (Guevara, 1982, p. 160).

Desde então, vários especialistas em diferentes áreas foram formados pelo CENIC, proporcionando significativas mudanças científicas e tecnológicas, além da criação de vários centros e institutos como, por exemplo, o Instituto de Ciência Animal, o Instituto de Física Nuclear, o Centro de Ciências Agrícolas, o Instituto de Recursos Minerais, o Centro de Automação Industrial, entre outros. No final dessa década, tiveram início os estudos na área da ciência da computação e foi criado o Centro de Investigação Digital (CID), vinculado à universidade, onde foi construído, em 1970, o primeiro computador cubano, o CID 201A.

A partir de então, teve início, na universidade, práticas de produção em centros de trabalho relacionados com a futura profissão e investigações científicas centradas em soluções de problemas reais, visando reduzir a distância entre trabalhadores manuais e trabalhadores intelectuais, entre população do campo e da cidade, entre gêneros e etnias. Em 1974, foi criado o Conselho Nacional de Ciência e Técnica. Além disso, escolas e institutos tecnológicos foram construídos nas áreas rurais, assim como o Instituto de Alta Tecnologia, com base científica em bioquímica, farmacologia e biotecnologia. Todas essas ações contaram com a assessoria dos soviéticos através do Consejo de Ayuda Mutua Económica (CAME). Nesse período, teve destaque a mudança socioespacial através da transformação técnica da produção agrícola, especialmente "de la agricultura cañera, así como por la restauración de capacidades en la producción azucarera y la creación de actividades de apoyo vinculadas a este sector" (Díaz-Balart, 2002, p. 416). Em setembro de 1976, foi criado o Complejo Científico-Docente Instituto Superior de Ciencias Agropecuarias (ISCAH), “(...) al cual se le otorgó la función de centro rector de la mayoría de las carreras agropecuarias en Cuba" (Lamar; Roach, 2018, p. 5).

Na década de 1980, aconteceu na universidade uma segunda mudança significativa, identificada por Jover e Quiñones (2016) como “el giro a la innovación”. Novos Centros foram criados, como o Centro de Engenharia Genética e Biotecnologia, Centro de Sanidade Agropecuária, Centro de Neurociência e o Centro de Imunoensaios. Como resultados 
tecnológicos desses centros, teve-se, por exemplo, o desenvolvimento de produtos para combater o câncer (Interferón); a imunização de jovens com menos de 25 anos contra a hepatite B através da vacina recombinante criada por métodos da engenharia genética; o desenvolvimento de vacinas recombinantes no combate ao carrapato no gado; vacinas combinadas tetravalentes que agem na prevenção da coqueluche, tétano, difteria, meningite e pneumonia; o desenvolvimento do Heberprot-P, medicamento para acelerar a cicatrização de feridas e ulceras crônicas de pacientes com diabetes, reduzindo o risco de amputação; criação de 28 estojos kits que permitem diagnosticar precocemente 17 doenças, dentre elas o hipotireoidismo congênito nas crianças; diagnóstico pré-natal de má formação congênita, a hiperplasia suprarrenal congênita e galactosinia.

Estes exemplos apresentados mostram que o processo revolucionário cubano construiu a realidade vislumbrada por Castro há mais de cinquenta anos, mesmo com as imensas dificuldades econômicas decorrentes do bloqueio estadunidense e do bloqueio oriunda da Rússia, devido ao fim do socialismo europeu e das crises capitalistas.

No período especial em tempo de paz, como foi denominado o período da grande crise cubana dos anos de 1990, foram criados o Polo Científico de Biotecnologia, o Ministério de Ciência e Tecnologia e Meio Ambiente e a Universidade de Ciências Informáticas. Neste período, segundo Dávila (2016), aconteceu o início da “(...) transformación de la generación de energía e introdujeron innovaciones en la producción de alimentos" (Dávila, 2016, p. 155). Além disso, a partir de 1994, houve a incorporação da inovação na política de ciência e tecnologia, chamada de Política de Ciência, Tecnologia e Inovação (PCTI) (Jover et al., 2015), cuja atenção foi orientada para o uso dos conhecimentos científicos e tecnológicos com ênfase na inclusão e equidade social. Neste período, o governo passou a incluir em suas ações os postulados da Conferência das Nações Unidas sobre o Meio Ambiente e o Desenvolvimento - Eco-92 - e a utilizar o discurso do desenvolvimento sustentável (PCC, 1993).

Em 1996, foi implantado o novo Sistema de Ciência e Inovação Tecnológica (SCIT), cujo principal objetivo declarado foi

(...) a la producción de bienes y servicios, sobre bases de eficiencia y competitividad, que condujeran a una economía moderna y a su inserción ventajosa en el mercado internacional. (...) En gran medida, el enfoque adoptado se ajusta bastante al modelo restringido de sistemas de innovación donde el sector de investigación-desarrollo (I+D) se coloca en el centro de la política (Jover et al., 2015, p. 213). 
Dessa política se destacam os vínculos entre universidade e empresa, a criação de empresas de base tecnológicas, bem como o desenvolvimento tecnológico nas áreas de ponta como a biotecnologia, a nanotecnologia, entre outras. Essa prática gerou as chamadas "paradojas de la innovación” (Jover, Arriete, 2015) que, como o próprio nome diz, desenvolveu várias contradições na política de inovação, pois tal política se caracterizou por ser uma política de cima para baixo, sem uma vinculação sistêmica entre os centros de investigações e as universidades, pautada em um conceito de inovação tradicional, que não implicava em mudança tecnológica (Jover; Arriete, 2013).

A partir das afirmações de Jover e Arriete (2013) sobre os paradoxos da inovação, surgiu a questão: qual a noção de ciência e tecnologia e de inovação que orientou as práticas efetivadas pelo governo revolucionário? Ao buscar resposta para a questão, pode-se constatar que a noção de ciência e tecnologia e inovação que orientava as ações dos responsáveis por tais áreas até os anos de 1990 estava ideintificada, prioritariamente, com a percepção instrumentral e determinista da tecnologia, que combina autonomia e neutralidade (Dagnino, 2006; Feenberg, 2010). Segundo Dagnino (2006), assim como na organizaão capitalista de produção, na Cuba revolucionária a ciência foi pensada como o instrumento que busca a verdade e a tecnologia como o instrumento que visa à busca da eficiência. Através da perspectiva determinista,

O avanço contínuo e inexorável da tecnociência (ou no seu jargão, o desenvolvimento das 'forças produtivas') seria a força motriz da história que, precionando as 'relações técnicas e sociais de produção', levaria a sucessivos e mais avançados 'modos de produção'. Para eles, a tecnociência não é controlada pelo Homem; é ela que, utilizando-se do avanço do conhecimento do mundo natural, verdadeiro e neutro, molda (e empurra para um futuro cada vez melhor) a sociedade mediante as exigências de eficiência e progresso que ela mesma estabelece (Dagnino, 2006, p. 8).

Essa percepção de neutralidade tecnológica fica evidenciada, por exemplo, no escrito de Guevara, de 1964, ao abordar o sistema orçamentário de financiamentos, que diz:

As formas de condução da economia, como aspecto tecnológico da questão, devem ser tomadas de onde estejam mais desenvolvidas e possam ser adaptadas à nova sociedade. A tecnologia da petroquímica do campo imperialista pode ser utilizada pelo campo socialista sem temor de contágio da ideologia burguesa. No ramo econômico (em tudo o que se refere a normas técnicas de direção e controle de produção) acontece o mesmo (Guevara, 1989, p. 59).

Ou seja, na perspectiva neutra, a tecnologia/tecnociência que está a serviço do capital e que oprime a classe dos trabalhadores é a mesma que, ao ser apropriada pela revolução 
socialista, a libertaria e construiria o ideal revolucionário socialista (Dagnino, 2006). A perspectiva da neutralidade da ciência e da tecnologia também fica evidenciada na fala de Manuel Limonta (cientista e fundador do Centro de Biotecnologia de Cuba), em entrevista concedida em 18 de julho de 2017, ao dizer que:

(...) não há desenvolvimento econômico se não houver desenvolvimento científico e tecnológico. Porém, o desenvolvimento tecnológico realizado em países com ideologia capitalista é pensado a partir da propriedade privada, em que grupos se unem e criam empresas e investem no desenvolvimento científico visando resultados que serão privados. Em Cuba, por sua vez, a preocupação e o interesse no desenvolvimento científico, tecnológico e educacional está no Estado e a motivação está em satisfazer a necessidade de todos visando melhor qualidade de vida para a população. Assim, no caso da alimentação, por exemplo, há que se ter em mente que a população está crescendo e o planeta é finito. Neste sentido, é necessário investigar para aumentar a produção de alimentos. Se a técnica do alimento geneticamente transformado for bem aplicada, bem focada, pensando nos seres humanos, pensando em facilitar a alimentação, ela pode trazer bons benefícios e não, necessariamente, ser daninha e não necessariamente produtora de câncer (Limonta, 2017, s/p).

A partir da segunda metade dos anos de 1990, Cuba passou a efetivar a política de criação dos Polos Científicos, cuja criação pode ser entendida como um feito fundamental para a integração da ciência, da inovação tecnológica e da produção, principalmente na área da biotecnologia. Para a sua criação, foram estabelecidos princípios básicos com o propósito de responder às necessidades econômicas e sociais do território e que demandam conhecimentos científicos e tecnológicos para efetivar ações desde a concepção até a comercialização de produtos. Uma de suas estratégias consistiu em realizar a inter-relação Universidade-Comunidade-Empresa, visando o desenvolvimento da

(...) formación y capacitación de los recursos humanos. Creación de un entorno idóneo para la interacción entre la investigación básica, la investigación aplicada y la innovación tecnológica. Lugares desde donde se potencie la creación de nuevas empresas tanto en los ámbitos universitarios como empresarias. Promotores e líderes que personifiquen los proyectos y posibiliten el surgimiento de bases tecnológicas, cuyas actividades coincidan con el perfil de las investigaciones de los centros de excelencias y de instituciones académicas (Cortez, 2011, $\mathrm{s} / \mathrm{p})$.

Resumidamente, o objetivo primordial dos Polos Científicos foi impulsionar o desenvolvimento econômico e social do país ou da região onde interagem seus principais atores, que são as universidades, as empresas e os governos. Com tais caraterísticas, foi criado, em 1991, o Polo Científico del Oeste de La Habana, com o objetivo de levar adiante o incremento da biotecnologia, da indústria médico farmacêutica e de tecnologias avançadas para solucionar problemas de saúde, alimentação e contribuir na obtenção de divisas para o 
país através de produtos competitivos. Posteriormente, foram criados os Polos temáticos Industrial e de Humanidades, ambos na capital de Cuba. Em 1992, foram criados os dois primeiros Polos Territoriais: um em Villa Clara e outro em Santiago de Cuba. Também foram criados novos Polos em outras províncias. Os Polos consistem em uma alternativa para a construção do desenvolvimento sustentável do território (Cortez, 2011).

Visando superar a PCTI da primeira metade dos anos de 1990, política que priorizava os vínculos entre universidade e empresa, com maior investimento nas áreas de tecnologia de ponta, sem uma vinculação sistêmica entre centros de investigação e universidades e com uma visão tradicional de inovação, grupos da universidade começaram, a partir de 1996, a se organizar para superar o modelo linear de inovação e construir novos espaços interativos de aprendizagem. A orientação voltava-se para a solução de problemas sociais relevantes, fundamentados em um sistema de inovação mais amplo que coloca a ênfase na aquisição e na utilização dos conhecimentos produtivos e inovadores, partindo do conceito de 'sistema de inovação', que engloba o conjunto de organizações que contribuem com o desenvolvimento de capacidades de inovação do país, da região e da localidade.

Assim, pode-se perceber que na prática cubana, até a primeira metade dos anos de 1990 a ciência, a tecnoloiga, a inovação e as técnicas de direção utilizadas no desenvolvimento industrial foram entendidas como neutras, pois muito se utilizou de experiências oriundas das práticas capitalistas. Porém, a partir da segunda metade dos anos 90, uma nova abordagem passa a fazer parte das políticas cubanas, sem, entretanto, romper com a busca no capitalismo para solucionar seus problemas científicos, tecnológicos e de inovação. Pelo menos uma parte dos profissionais da ciência, da tecnologia e da inovação deixam de pensa-las como neutras e buscam novas práticas sociais, econômicas e ambientais.

Paulatinamente, houve a intensificação do enfoque na agricultura sustentável como diretriz tecnológica fundamental da política agrícola, em consonância com a Agenda 21 e em oposição aos ideários da Revolução Verde em vigor desde a implantação do governo revolucionário. A essa mudança, Lamar; Roach (2018) chamam de "giro epistemológico", em que os ensinamentos dos cursos universitários passaram a ter por base os princípios da agroecologia, da sustentabilidade, do enfoque holístico, da interdisciplinaridade com ênfase no desenvolvimento local sustentável e com uma perspectiva mais crítica da ciência e da tecnologia. 
Foi nesse período que se implantou o fomento do desenvolvimento endógeno e local, e foi reorganizado o sistema de ciência e inovação tecnológica com o ideal de “(...) mayor especialización, integración y aplicación de los logros en ciencia y tecnología (sobre todo biotecnológicos) encarnó en el sistema de Polos Científico-Tecnológicos" (Lamar; Roach, 2018, p. 4). Em diversos cursos universitários, foi introduzindo o ensinamento sobre Problemas Sociais da Ciência e da Tecnologia (PSCT). Segundo Lamar e Roache (2018),

(...) esta materia de PSCT es la forma en que se recepcionó en Cuba la reflexión globalizada en materia de Epistemología, Cienciología, Filosofía de la Ciencia, Filosofía de la Tecnología, Sociología del Conocimiento, los Estudios Sociales de la Ciencia y la Tecnología o Ciencia, Tecnología y Sociedad (Estudios CTS) (Lamar; Roache, 2018, p. 9).

Ademais, ela colocou em xeque a visão positivista, cientificista, desenvolvimentista

objetivista y universalista de la ciencia y la tecnología, el progreso científico, el progreso tecnológico, y sus relaciones con el progreso social. Paulatinamente, a especialización disciplinar pasa a dar lugar a un saber interdisciplinar, integral e versátil proporcionando un enfoque holístico sobre os problemas e o desarrollo locales. O slogan que caracterizaba esta nova realidad era: “iEl municipio se convierte en una gran aula!” (Lamar; Roache, 2018, p. 7)

A partir dessa perspectiva, a inovação, para vários formuladores da política, passou a ser entendida como um fenômeno interativo, convergindo fatores sociais, políticos, institucionais e culturais, em que se afirma o caráter interdependente - em rede - e de não linearidade nos processos de inovações. Nessa proposta, a aprendizagem é considerada um meio fundamental de inovação e passa a requerer uma forte interação entre universidade, centros de investigação, todos os níveis de governo, regulações jurídicas, sistema educativo. Além disso, a atenção está centrada nos Arranjos Produtivos Locais (conjunto de empresas produtivas de insumos e equipamentos, de consultoria e serviços), que atuam em um mesmo espaço geográfico e em interação com outros atores locais tais como: instituições públicas e privadas, escolas, universidade, instituições de investigações, financiamento, entre outras (Reyes; Martínez; Rodríguez, 2011) e no conjunto de atores que participam do processo de inovação.

Assim, gradativamente, foi se desenvolvendo no interior da universidade cubana a perspectiva que pensa a sociedade para além do mercado. O conhecimento e a ciência até podem se voltar para as demandas comerciais, porém, devem, principalmente, voltar-se para as necessidades sociais. Assim, a partir do modelo interativo, fica facilitada a participação da universidade no sistema de inovação, em que os papéis da universidade podem ser: 
1) Provee a los graduados universitarios. 2) Asegura educación de posgrado. 3) Ejecuta una parte importante de las actividades de investigación y desarrollo del país. 4) Participa de la construcción de las políticas públicas. 5) Es responsable del entrenamiento de ejecutivos. 6) Contribuye a apoyar estrategias locales de desarrollo (Jover; Arriete, 2014/2015, p. 36).

Visto estes aspectos sobre a universidade com sua produção de ciência, tecnologia e inovação que deixou de ser vista apenas como neutra para aglutinar também a visão crítica, cabe-nos, a partir de agora, tecer considerações sobre a ciência, tecnologia e inovação que contribuem para o DLSC no século XXI.

\section{A Universidade com sua Ciência, Tecnologia e Inovação no Século XXI}

Uma primeira mudança que aconteceu nas universidades de Cuba no início do século XXI, especificamente a partir de 2002, foi denominado por Jover et al. (2015) de "giro territorial", cujo principal aspecto foi a criação das Sedes Universitárias Municipais (SUM) em 169 municípios, possibilitando a municipalização do ensino superior. "Su tarea fue la de ofrecer estudios de pregrado en carreras preferentemente de ciencias sociales y humanidades, que podían desarrollarse con recursos relativamente modestos" (Jover, Arriete, 2014/2015, p. 37). Desde então, Cuba passou a ter um sistema nacional de pós-graduação e uma rede de universidades e centros de 'Investigação + Desenvolvimento + Inovação' (I+D+I) em todo território nacional. Além disso, as universidades criaram mecanismos para facilitar a inovação tecnoprodutiva e social, cuja agenda de investigação e formação passou a se vincular com as necessidades do desenvolvimento social (Jover, 2017).

Atualmente, as antigas SUM são chamadas de Conselhos Universitários Municipais (CUM) e atuam como aglutinadores de patrimônio humano e inovador do local; como agentes de conhecimento que ajudam a pensar o local; participam na elaboração de estratégias de desenvolvimento apoiados no conhecimento; participam na formação de recursos humanos; identificam arranjos produtivos locais e refletem sobre os conhecimentos e as tecnologias necessários para o desenvolvimento local; promovem nos atores locais uma visão integrada e holística do desenvolvimento local com a orientação do desenvolvimento sustentável, equitativo e inclusivo. Para Jover, em entrevista concedida em 20 de julho de 2017, "a tecnologia é, essencialmente, conhecimento que deve ser produzido, disseminado e usado sempre em função da solução criativa de problemas básicos, como por exemplo, de água, alimentação, habitação, saúde etc (Jover, 2017). 
Em sua perspectiva de 'ciência integrada', a ciência e a tecnologia são entendidas como processos sociais que devem existir para beneficiar os grupos humanos, ampliar seus conhecimentos e melhorar a qualidade de vida. A inovação, por sua vez, passou a ser entendida e difundida como o "conjunto de organizaciones que contribuyen al desarrollo de capacidades de innovación de un país, región, sector o localidad. Se constituye de elementos y relaciones que interactúan en la producción, difusión y uso del conocimiento" (Jover; Arriete, 2014/2015, p. 31). Para estes autores, inovar é "aprender a producir y usar conocimiento nuevo o aprender a combinar y utilizar conocimientos existentes, en nuevas formas, ante viejos y nuevos problemas" (Ibidem, p. 31).

A inovação que daí resulta é aquela que se volta para as soluções criativas de velhos e novos problemas nos setores produtivos material, cultural e simbólico, bem como na organização de governança em âmbito local. Esse tipo de inovação é denominado de “(...) Sistemas de Innovación Local (SIL) que, por sua vez, é definido como "un conjunto de elementos y relaciones que interactúan en la producción, absorción, difusión y uso de conocimientos para fines de interés social” (Jover; Quiñones, 2016, p. 201).

A partir de 2006, professores universitários juntamente com membros do Ministério da Educação Superior (MES) criaram o Programa de Gestión Universitaria del Conocimiento y la Innovación para el Desarrollo (GUCID), visando aproximar o ensino superior com o Desenvolvimento Local. A partir de então, as universidades passaram a ampliar as agendas com temas do desenvolvimento local e articulá-los com as atividades de ciência, tecnologia e inovação. Sobre a tecnologia, Jover, outros membros da equipe do GUCID dizem que ela é mais que uma ciência aplicada e não é apenas artefato. Ela inclui conhecimentos e práticas sociais e pode ser definida como:

(...) una actividad humana que tiene lugar en contextos socio-históricos y que no se rige por un modelo unidireccional unívoco causa-efecto en donde el desarrollo científico sea condicionante exclusivo del desarrollo tecnológico. Incluye conocimiento del usuario, conocimiento tácito, entre otros. Nada es absolutamente tecnológico, lo social siempre está presente. Por eso las tecnologías no funcionan igual en todas las sociedades y contextos (Jover; Quiñones, 2016, p. 196).

Em entrevista concedida em La Habana, em 20 de julho de 2017, Jorge Nuñes Jover disse que, na perspectiva do GUCID,

(...) ao se falar em tecnologia e inovação, se está falando sobre a aprendizagem do produtor, sobre o centro de investigação universitário trabalhando conjuntamente com os camponeses para buscar melhor qualidade de sementes. Se está falando sobre a articulação entre 
universidade e governos locais para melhorar a participação social na governabilidade assim como, no desenvolvimento territorial local. Nesta perspectiva, a inovação é pensada para além do mercado, defendida como a solução criativa de problemas não, apenas, material, mas também, simbólico e cultural e ela acontece pela inter-relação entre produtores, usuários, pesquisadores, buscando uma continuidade entre aprendizagem-inovação-solução criativa e bem-estar humano (Jover, 2017, s/p).

Nesse mesmo sentido, prossegue Jover afirmando que

(...) quando pensamos sobre tecnologia nos distanciamos daquela visão que pensa a tecnologia como somente um artefato e na alta tecnologia. Pensamos a tecnologia como sendo, essencialmente, conhecimento que deve ser produzido, disseminado e usado, sempre, em função de soluções criativas de problemas de qualidade da água, moradia, saúde, ou seja, em função de problemas da população, vinculada com orientações científicas e pela perspectiva social. Ao se pensar em tecnologia há que se pensar nos interesses que estão orientando a tecnologia: se a orientação é o social ou é a lucratividade. Na orientação reside a sua aplicação. As universidades e o centros de investigação estão ampliando as orientações tecnológicas e da inovação no sentido de privilegiar o desenvolvimento local (Ibidem, s/p).

Apresentadas estas considerações sobre universidade com sua ciência, tecnologia e inovação, passamos agora a apresentar situações concretas da relação destas instituições com o desenvolvimento local em Cuba.

\section{Casos Exitosos da Aproximação da Universidade com o DLSC}

Como exemplos profícuos da relação entre universidade e Desenvolvimento Local, apresentam-se algumas redes sócio-técnicas exitosas em Cuba. O primeiro exemplo é o da Rede de Eco-materiales para el Hábitat Sostenible da Universidad Central de Las Villas, que atua no sentido de minimizar o déficit habitacional cubano devido, principalmente, aos fenômenos meteorológicos (Jover, et al., 2015). Participa ativamente dessa rede o Centro de Investigación y Desarrollo de Estructuras y Materiales (CIDEM) - criado em 1992, na Universidade Central de Las Villas -, com a missão de investigar materiais de construção para habitação. Em 2007, o projeto recebeu o Prêmio Nacional de Inovação Tecnológica e, em 2011, o prêmio "Pergamino de Honor", outorgado pela Habitat das Nações Unidas - a mais prestigiosa distinção que se outorga aos assentamentos humanos em todo o mundo.

A rede está sustentada em uma tecnologia habitacional que visa à fabricação em escala municipal, mediante recursos e matérias-primas locais, na qual participa governo municipal, instituições do setor de moradia, famílias beneficiadas, universidades dentre outros setores. A produção dos materiais tem por base um pacote tecnológico que o CIDEM denomina de "eco 
materiais", devido aos seus benefícios econômicos e ambientais, dos quais se destacam o cimento puzolamico CP40 e as telhas de micro concreto ${ }^{3}$.

O segundo exemplo de êxito da relação entre universidade e Desenvolvimento Local refere-se ao Programa de 'Innovación Agropecuario Local', que visa à produção de alimentos através da solução de dois desafios: 1) fazer uma agricultura de baixos insumos e com princípios ecológicos e 2) substituir a importação de alimentos para alcançar a autonomia alimentar. Nessa experiência, um dos atores que se destaca é o Instituto Nacional de Ciencias Agrícolas (INCQ), fundado em 1970, com a missão de “(...) generar y transferir conocimientos actualizados, tecnologías integradas y nuevos productos de biotecnología, ciencia vegetal y sistemas sostenibles para aumentar la producción agrícola" (Jover et al., 2015 , p. 236) ${ }^{4}$. Uma das áreas de trabalho é o melhoramento genético das plantas, que acontece através do Programa de Diseminación del Fitomejoramiento Participativo (FP) em Cuba, envolvendo a participação do INCA, de outras instituições acadêmicas e produtores de cooperativas agropecuárias que trabalham no melhoramento de sementes de milho, feijão e arroz. O FP desenvolve diagnósticos locais, feiras locais de biodiversidade e fomenta processos de experimentação agrícola. Sua filosofia diz que “(...) no existen semillas mejores o peores; existen semillas para diversas culturas y diversos agrossistemas" (Ibidem, p. 237).

Na segunda fase do programa de FP, foi desenvolvido, a partir de 2007, o Programa para fortalecer a Inovação Agropecuária Local (PIAL), visando apresentar soluções complementares para aumentar a segurança e soberania alimentar local. A rede PIAL tem disseminado em dez províncias do país espécies, variedades e tecnologias em consonância com o meio ambiente, proporcionando assim o empoderamento e a participação dos agricultores, assim como o enfoque de gênero, que busca ampliar a equidade e visibilidade do papel produtivo das mulheres no contexto rural.

O trabalho em rede teve sua consolidação com a criação dos Centros Locales de Innovación Agropecuaria (CLIA), tendo em vista o alcance obtido na constituição de uma massa crítica facilitadora da inovação agropecuária local. Por essa via, foi possível a participação multisetorial no desenho, construção e implantação de tecnologias locais. O PIAL tem proporcionado processos de desenvolvimentos inclusivos através da promoção de

\footnotetext{
${ }^{3}$ Ver www.ecosur.org/index.php/ecomateriales/cimento-puzol\%c3\%A1 nico/40-calidad-del-cp-40

${ }^{4}$ Ver também: www.inca.edu.cu
} 
espaços participativos. Nesse sentido, o Programa atua como interface entre a investigação científica e a transformação real nos contextos locais.

En términos de soberanía alimentaria, el programa ha disminuido los niveles de dependencia externa de las producciones, promovido el liderazgo de los campesinos y aumentado el rendimiento de cultivos y animales. En términos de calidad de vida, los campesinos incorporados han multiplicado el valor del autoconsumo familiar, diversificado su alimentación en base a frutas y vegetales, mejorado el estado constructivo de sus casas y superado algunos niveles de desigualdad de género (Jover et al. 2015, p. 240).

Finalmente, o último projeto que se destaca na práxis do Desenvolvimento Local de Cuba é o Projeto Biomas Cuba, de 2008. Ele constitui uma alternativa socioeconômica fundada na agroecologia e na biomassa como fonte renovável de energia, ajudando na melhoria das condições de vida da população rural. O projeto visa o desenvolvimento de alternativas tecnológicas locais para a geração de energia, com o objetivo de reduzir o uso de combustíveis fósseis e, consequentemente, promover benefícios ambientais.

\footnotetext{
Las alternativas tecnológicas que despliegan apuntan a la producción de biogás y su aplicación directa como combustible o transformándolo en energía eléctrica a partir de desechos del agroecosistema. Persigue también la producción y utilización de biodiesel a partir de plantas oleaginosas no comestibles y sus productos derivados para la alimentación animal y la gasificación de residuos agroforestales y agrícolas para la producción de electricidad en pequeñas comunidades rurales aisladas del sistema energético nacional. Dichas alternativas se encuentran en marcha en 14 municipios pertenecientes a 5 provincias del país (Jover et al., 2015, p. 241).
}

Esses exemplos explicitam que a educação superior pode servir de ponte entre o conhecimento, a ciência e a tecnologia para o Desenvolvimento Local, $\mathrm{cm}$ destaque para uma ciência e uma tecnologia que no Brasil são adjetivadas de social. Além disso, as inovações se apoiam e promovem a investigação científica que facilitam os fluxos dos conhecimentos e tecnologias alternativas. Assim, o contexto local tem demandado não só aprendizagem transdisciplinares, mas também, o diálogo com produtores agricultores, portadores dos seus próprios saberes e experiências. Os casos mostram também o papel da educação superior como promotora “(...) de tecnologías que ayudan a resolver problemas sociales y conectan directamente con las necesidades cotidianas de las personas, respaldando dinámicas de inclusión, equidad y bienestar" (Jover et al., 2015, p. 245).

Vistos os aspectos que consideramos relevantes para a compreensão do papel da Universidade com sua ciência, tecnologia e inovação no desenvolvimento local cubano, passaremos agora a discorrer sobre um outro ator social que desempenha importante papel no 
processo de efetivação do Desenvolvimento Local Sustentável Cubano, qual seja: o Fórum de Ciência e Técnica.

\section{Fórum de Ciência e Técnica}

A ideia do fórum surgiu em dezembro de 1980, com Fidel Castro, quando, diante do bloqueio estadunidense e da dificuldade de se obter peças de reposição, houve um consequente aumento de gastos com a importação das mesmas. Efetivamente, o fórum surgiu em 1981 com a denominação de "Forum Nacional de Piezas de Repuesto", visando impulsionar a fabricação e recuperação de peças para diminuir a necessidade de importações. Essa atividade foi organizada com todos os ministérios que, de alguma forma, lidavam com a necessidade de peças de reposição. Juntos, criaram a Comissão Nacional de Peças de Reposição, que aglutinou trabalhadores experientes, tecnólogos e engenheiros de diferentes ramos da indústria, buscando, de forma voluntária, solucionar problemas referentes às peças de reposição.

A Comissão Nacional, não é uma instituição estatal nem administrativa. Para alguns, ela é um movimento com espírito de cooperação que resultou da necessidade de desenvolvimento do país, tornando-se uma espécie de instrumento político-ideológico para o trabalho. Além disso, ela pretende a integração da ciência com a técnica na busca de soluções práticas que demandam no dia-a-dia das empresas e dos serviços. No ano de 1986, durante a realização do IV Fórum, a denominação passou para "Forum de Piezas, Equipos y Tecnologías Avançadas"; já no VII Fórum, passou a ter a denominação de "Forum Nacional de Ciencia y Técnica”, cujo objetivo fundamental foi o de “(...) impulsar la introducción y generalización de los avances científico-técnicos en el país por medio de un movimiento masivo que agrupa a miles de creadores en Cuba" (Díaz et al., 2005, p.2). Cabe ressaltar que o VII Fórum aconteceu no período denominado de "período especial em tempo de paz", quando Cuba passa a viver o segundo bloqueio originado pelo fim do socialismo europeu e que resultou na perda de produtos oriundos do bloco socialista.

Para Maria de Carmem Barroso Gonçale, diretora do Departamento de Relações Internacionais da Asociación Nacional de Agricultores Pequeños (ANAP), em entrevista concedida em 3 de agosto de 2017 , 
(...) Os Fóruns de Ciência e Técnica existem por que não foi possível outra opção. Ele serviu e serve para solucionar problemas que não podem ser solucionados devido ao bloqueio. Ele acontece desde a base, na cooperativa ou na fábrica, em âmbito municipal, provincial e nacional (Gonçale, 2017, s/p.).

Sua organização começa a partir do Fórum de Base, que acontece no âmbito das empresas e/ou instituições em que participam pessoas com diferentes níveis de qualificação técnica e acadêmica, constituindo dois grupos: um conhecido por 'jovens criadores' (composto por pessoas de ambos os sexos e com até de 35 anos), que constitui as "Brigadas Técnicas Juveniles" (BTJ), também denominados de Brigadistas; e o grupo formado por criadores de ambos os sexos (com mais de 35 anos), que constituem os "Comites de Innovadores y Racionalizadores" (CIR), também denominados de Aniristas. Os dois grupos trabalham em estreita colaboração com uma determinada instituição, que conta com um "banco de problemas", construído por aqueles que na instituição atuam. Os aniristas, a partir do banco de problemas, elaboram um plano temático para obtenção das respectivas soluções, com a efetiva participação dos brigadistas. Os trabalhos passam por um processo de seleção e os selecionados são enviados ao Fórum municipal.

No Fórum municipal é desenvolvido um programa de atividades parecido com o que se realiza na base, com um evento técnico em que são escolhidos os trabalhos que serão enviados ao Fórum Provincial, que é realizado a cada dois anos. Anualmente, é elaborado um resumo das conquistas obtidas e dos problemas que continuam pendentes. Após o Fórum Provincial, acontece o Fórum Nacional (a cada dois anos), em que são recebidos os trabalhos selecionados nos Fóruns das províncias. Acontece, então a socialização dos resultados das inovações e racionalizações, realizadas no país em seus distintos níveis.

Para Jover, em entrevista realizada em 20 de julho de 2017, em La Habana,

O Fórum de Ciência e Técnica é uma experiência que acontece em diferentes espaços laborais em que as pessoas têm que encontrar soluções para os problemas que lhes aparecem constantemente. Seja pela necessidade de substituir uma matéria-prima que falta, ou precisando repor peça de uma máquina que não se consegue devido aos problemas de importação. Há que se aprender novas coisas para aumentar a produção, há que se ter conhecimento para o melhor funcionamento de qualquer organização. O Fórum é relevante, pois, coloca em evidência, articula, organiza e reconhece o esforço de pessoas que trabalham em organizações e que não estão diretamente envolvidas com a inovação. Porém, aqui não se está falando de inovação vinculada à inovação mais Desenvolvimento, necessariamente. Não se está falando em inovação high tech. Estamos falando de inovação em âmbito laboral, onde o Fórum é o espaço que permite, periodicamente, que os trabalhadores ponham sobre a mesa o como será feito para que as empresas funcionem e isso, de forma horizontalizada em que o trabalhador, o engenheiro, o cientista debatem e decidem conjuntamente sobre os rumos da organização (Jover, 2017). 
Em âmbito nacional, o Fórum se articula com a Asociación Nacional de Innovadores y Racionalizadores (ANIR), que acionam os brigadistas e, juntamente com os aniristas, aperfeiçoam, divulgam e generalizam as devidas soluções apresentadas desde a base. Participam do Fórum de Ciencia y Técnica muitas instituições dedicadas à investigação, à docência, à produção e à assistência. Tais instituições constituem os grupos de cooperação tecnológica. Esses, no âmbito das províncias, difundem e revisam as soluções com as direções administrativas, e propõem a

(...) incorporación a los bancos de soluciones generalizables y a planes de generalización. Los planes de generalización recogen los resultados de las innovaciones y racionalizaciones realizadas en cada entidad y programan su introducción, tanto en la entidad creadora como en otras organizaciones que puedan servirse de ellas (Díaz et al., 2005, p.4).

Em 1993, foi realizado o VIII Fórum, o primeiro denominado Fórum de Ciencia y Técnica, cuja tarefa central era investigar os problemas do armazenamento de combustíveis, eletricidade e eficiência energética, considerando as dificuldades que o país vivia no período especial. No IX Fórum (1994), foram inscritos duzentos e sessenta e três mil trabalhos com um milhão de participantes. No século XXI, o Fórum amadurece na organização, atingindo maior diversidade, intensidade e sistematicidade, aproximando-se do Ministerio de Ciencia, Tecnología y Medio ambiente. A partir daí ele passou a ter uma direção colegiada, além de ser incorporado aos controles governamentais, aumentando, assim, a participação dos ministérios. Em 2013, os principais temas de trabalho foram: economia, eficiência energética e energia renovável; generalização de soluções úteis e substituição de importações; produção de alimentos, saúde, educação, informática, biotecnologia, indústria farmacêutica; e cuidado com o meio ambiente.

Embora não existam metas previamente estabelecidas, seja por parte do Estado ou pela direção de uma determinada instituição, pois o Fórum começa com os problemas oriundos na base, visando criar o ambiente necessário para buscar soluções aos problemas que incidem negativamente nos objetivos da instituição e, assim identificar e confeccionar o banco de problemas para a realização das respectivas propostas de soluções, cada Comissão Nacional, da província ou do município está presidida por um dirigente do governo e, por isso, o Movimento do Fórum acaba sendo orientado e guiado pelo Partido Comunista. Há que se destacar, contudo que o Movimento não se guia pelas regras do mercado ou por mecanismos 
mercantis: "Su esencia es la cooperación con espíritu socialista y solidaridad humana y revolucionaria" (Forum De Ciência Y Técnica) ${ }^{5}$.

Em 2018, aconteceram vários Fóruns de base, por exemplo, o da Universidad Central "Marta Abreu" de Las Villas, realizado entre abril e setembro daquele ano, com as seguintes prioridades de investigação:

1) Producción de alimentos, especialmente de alimento animal; 2) Energía, con prioridad a las renovables; 3) Medio ambiente y el impacto del cambio climático en Cuba; 4) Informatización y automatización de la sociedad cubana; 5) La situación demográfica, con el envejecimiento de la población; 6) El agua y los recursos naturales; 7) El desarrollo territorial urbano; 8) La industria satelital; 9) La sustitución de las importaciones de materias primas y piezas de repuesto en la producción de medios de enseñanza; 10) El incremento de la producción De Software Y Videos Educativos Para La Docencia Y El Extensionismo De Resultados De I+D (Vigo, 2019, s/p).

Outro exemplo de Fórum que aconteceu em 2018 foi o XII Fórum de Ciencia y Técnica do Centro Nacional de Información de Ciencias Médicas (CNICM), em 31 de maio de 2018, na cidade de La Habana, cuja convocatória continha o seguinte texto:

El Consejo de Dirección, el Partido, La Juventude y el Sindicato del CNICM; invita a los trabajadores a presentar trabajos de innovación que aborden soluciones para los principales problemas de investigación de nuestro Centro (Médicas, 2019, s/p).

Em 2020 acontecerão os Fóruns nacionais. Não é difícil imaginar as importantes contribuições que o Fórum de Ciencia y Técnica proporcionará ao Desenvolvimento Local. Através dele, foram e serão elaboradas significativas soluções de problemas para as fábricas, escolas, hospitais e outras instituições da localidade, posteriormente implantadas em outras realidades que por ventura tenham necessidades de tais soluções.

\section{Considerações Finais}

Em Cuba, como foi demonstrado, podemos identificar uma política de Estado voltada para a realização do Desenvolvimento Local utilizando-se de estratégias que se identificam com a visão de ciência, tecnologia e inovação desenvolvidas pela universidade que não parte, apenas, da racionalidade capitalista de produção. Ministérios, universidades, Fórum de Ciência e Técnica e outros atores e espaços públicos estão voltados para a realização do

\footnotetext{
${ }^{5}$ https://www.ecured.cu/Forum_de_Ciencia_y_T\%C3\%A9cnica
} 
Desenvolvimento Local Sustentável, e isso demonstra a capacidade de reinvenção do povo e do Estado cubano diante das dificuldades enfrentadas, principalmente, pelos bloqueios impostos ao país. Entretanto, não podemos dizer que em Cuba existe tecnologia socialista.

Vimos que, pela história pós-revolução, a universidade passou por importantes mudanças identificadas pelos chamados 'giros' da investigação, da inovação, epistemológico e territorial. A partir do conteúdo apresentado, concluímos que houve um momento em que a produção do conhecimento deixou de se voltar, de forma preponderante, para o mercado, para a tecnologia de ponta e para a exportação, passando a ser orientanda para a solução dos problemas concretos e básicos da população e para o Desenvolvimento Local e para a agroecologia com princípios da sustentabilidade. Porém, embora haja algumas poucas especificidades, a ciência, a tecnologia e a inovação em muito se identifica com o que se produz no campo capitalista.

Isso se verifica na proposta do desenvolvimento local cubano cuja origem está na organização capitalista de produção. Aliás, medidas adotadas pelo socialismo cubano, cuja origem está no viés capitalista, não foram poucas. Na busca de solução para os efeitos do bloqueio estadunidense, dentre eles, a falta de soberania alimentar, Cuba adotou os princípios da revolução verde, só mudando tal postura no final do século XX, quando passou a adotar gradativamente os princípios da agroecologia baseados na Agenda 21, que se fundamentam no desenvolvimento sustentável da Comissão Mundial Sobre Meio Ambiente e Desenvolvimento e que em nada rompe com o modelo capitalista de produção. Além disso, no socialismo cubano, a visão de neutralidade da ciência, da tecnologia e da inovação, que foi e é comum na realidade capitalista, fizeram e ainda faz parte do seu contexto. Assim, arriscamos afirmar que Cuba, no seu processo de construção do socialismo, vive um processo em que se identificam, simultaneamente, práticas socialistas, na medida em que a propriedade dos meios de produção em sua maioria é controlada pelo Estado, e práticas oriundas do capitalismo, tais como, a busca pela sustentabilidade, o desenvolvimento local e outras estratégias mais.

Podemos concluir, também, que os cubanos vêm se esforçando para encontrar soluções dos seus problemas locais sem perder o ethos socialista, embora este esteja enfraquecido, através de setores da universidade que buscam reforçar o desenvolvimento local sem a privatização dos setores produtivos. Além disso, a experiência do Fórum de Ciência e Técnica, que é uma especificidade de grande relevância no processo cubano de 
desenvolvimento científico e tecnológico, demonstra a prática da democratização na construção de novas tecnologias que se opõem, efetivamente, à produção de tecnologia convencional capitalista. Além disso, por viverem o processo de construção do socialismo há 60 anos, os cubanos internalizam/expressam mais intensamente os princípios da solidariedade e da preservação ambiental. Vivenciam e desenvolvem tecnologias e inovação voltadas para o Desenvolvimento Local. Buscam soluções tecnológicas para as empresas e instituições locais através do Fórum de Ciência e Técnica e, de certa forma, mantêm acesa a chama dos ideais socialistas na América Latina.

\section{Referências}

ALBELO, Víctor Manuel Figueroa. Transición extraordinaria del capitalismo al socialismo en Cuba. 2006. Disponível em: http://www.eumed.net/libros-gratis/2006b/vmfa/2c.htm. Acesso em: 28/12/2018.

ALFONSO, Julia Matilde Campos. "Cuba frente al desarrollo local: consideraciones teóricometodológicas y reflexiones para su aplicación”. Revista Economía e Desarrollo. La Habana, v.146, n. $1 \quad-\quad$ 2, jan./dez. 2011. Disponível em: https://www.redalyc.org/comocitar.oa?id=425541315002. Acesso em: 22 jun. 2019.

CASTRO, Fidel. "Discurso pronunciado por el Comandante em Jefe Fidel Castro Ruz en la Demajagua, em 10 de octubre de 1968”. In: GONZÁLES, Ana Lamas; SUÁRES, Gladys Lópes. Antecedentes históricos de la Revolución Socialista de Cuba. La Habana: Ministerio de la Educación Superior/ENPES, 1987.

Discurso pronunciado en la clausura del VI Foro Nacional de Piezas de Repuesto, Equipos y Tecnologias de Avanzada, efectuada en el palacio de las convenciones, el 16 de diciembre de $1991.1991 . \quad$ Disponível em: http://www.cuba.cu/gobierno/discursos/1991/esp/f161291e.html. Acesso em: 21 jun. 2019.

CEBALLOS, Gliceria Gómez. "La gestión de proyectos como interface de la ciencia y la innovación para el desarrollo económico local. Una experiencia desde la Universidad de Pinar del Rio, Cuba". Revista Economía e Desarrollo. La Habana, v. 146, n.1 - 2. 2011. p.189 210.

CORTEZ, Liliana Suárez. "La relación entre Parques Científicos Tecnológicos y los Polos Científicos de Cuba como un espacio significativo en la formación de capacidades científicas para el desarrollo de 
la I+D+I”. Revista Contribuciones a las ciencias sociales. Málaga, jan. 2011. Disponível em: http://www.eumed.net/rev/cccss/11/lcs.htm. Acesso em: 11 jun. 2019.

DAGNINO, Renato. "Conversa com um engenheiro que esteve em Cuba (ou uma reflexão sobre as dificuldades cognitivas para conceber a política universitária e de C\&T a partir do contexto sócioeconômico)". Revista de Ciência da Informação - v.7 n.1 fevereiro, 2006.

DÁVILA, Agustín Lage. "Ciencia y desarrollo: la encrucijada de los cubanos". Revista Cuba Socialista. La Habana, v.4, n.2, 2016. p. 154 - 165.

DÍAZ-BALART, Fidel Castro. Ciencia, innovación y futuro. Barcelona: Editora Grijalbo, 2002.

DÍAS, Elena Blanco. “Obstáculos a vencer en el desarrollo local. Estudio de caso: municipio Guanabacoa". Revista Economía e Desarrollo, v.151, n. 1 jan./jun.. 2014. p. 187-197.

DİAZ, Santovenia et al. Forum de ciencia y técnica: las bibliotecas al servicio de la innovación científica y tecnológica en Cuba. La Habana: Acimed, 2005. Disponível em: http://bvs.sld.cu/revistas/aci/vol13_3_05/aci11305.htm. Acesso em: 15 jun. 2019.

FEENBERG, Andrew. "Racionalização subversiva: tecnologia, poder e democracia". In: NEDER, Ricardo Toledo. (org). A teoria crítica de Andrew Feenberg: racionalização democrática, poder e tecnologia. Brasília: Observatório do Movimento pela Tecnologia Social na América Latina / CDS / UnB / Capes, 2010.

GONÇALE, Maria de Carmem. Entrevista realizada em La Habana, 2017.

GUEVARA, Ernesto. Che Guevara, textos econômicos: para a transformação do socialismo. São Paulo: Edições Populares Analdino Rodrigues Paulino Neto, 1982.

GUEVARA, Ernesto. O socialismo humanista. Petrópolis: Vozes, 1989.

JOVER, Jorge Nuñes. Entrevista realizada em La Habana, 2017.

JOVER, Jorge Nuñes; QUIÑONES, Ariamnis Alcazar (Coord.). Universidad y desarrollo local: contribuciones Latinoamérica. México: UDUAL; Habana: Editorial Universitaria Félix Varela/ Ministerio de Educación Superior, 2016.

JOVER, Jorge Nuñes; ARRIETE, Luis Félix Montalvo. "La política de ciencia, tecnología e innovación en Cuba y el papel de las universidades". Revista Cubana de Educación Superior. La Habana, v. 34, n.1, sep-dic. 2014/ ene-abr. 2015. p. 29 - 43.

JOVER, Jorge Nuñes et al. "Educación superior, innovación y desarrollo local: experiencias en Cuba”. Revista Congreso Universidad. La Habana, v. 4, n.5, jan. 2015. p. 228 - 248. 
JOVER, Jorge Nuñes; ARRIETE, Luis Félix Montalvo.” La política de ciencia, tecnología e innovación en la actualización del modelo económico cubano: evaluación y propuestas". Revista Economía y Desarrollo. La Habana, v. 150, n. 2, jul-dic. 2013. p. 67 - 82.

LAMAR, Adolfo Ramos; ROACH, Eduardo Francisco. "El giro epistemológico en la universidad agraria de La Habana (UNAH), Cuba”. Revista Internacional de Educação Superior. Campinas, v.4, n.2, maio/ago. 2018.

LIMONTA, Manuel. Entrevista realizada em La Habana, 2017.

MÉDICAS, Centro Nacional de Información de Ciencias. XII Fórum de Ciencia y Técnica 2018. Disponível em: http://forocnicm.sld.cu/index.php/foro2018/2018. Acesso em: 22 jun. 2019.

PCC. VI Congreso del Partido Comunista de Cuba: información sobre el resultado del debate de los Lineamientos de la política económica y social del partido y la revolución. La Habana, 2011.

. VII Congreso del Partido Comunista de Cuba: actualización de los Lineamentos de la política económica y social del partido y la revolución para el período 2016-2021. La Habana, 2016.

. Lo extraordinario UNE a los Hombres: proceso electoral cubano. La Habana: Editora Política, 1993.

PÉREZ, Maricela M. Gonzáles et al. "Redes de gestión del conocimiento universidadgobierno para el desarrollo local. Experiencias de innovaciones organizacionales e institucionales en los municipios de la provincia de Pinar del Río, Cuba". In: JOVER, Jorge Núñez e QUIÑNONES, Ariamnis Alcazar. Universidad y desarrollo local: contribuciones latinoamericanas. México: UDUA; Habana: Editorial Universitaria Félix Varela, 2016.

PÍREZ, Pedro Matínes. Entrevista realiza em 14 de julho, La Habana, de 2017.

REYES, Rafael M., MARTÍNEZ, Yariel, RODRÍGUEZ, Silvia C. "La universidad cubana, gestión de conocimiento, tecnología y sociedad. Su modelo educativo en la experiencia de Yaguajay". Revista Economía y desarrollo, v. 146, n.1-2, 2011.

SEGURA, Carmen Magaly León; LÓPES, Odalys Peñate. “Territorio y desarrollo local”. Revista Economía y desarrollo. La Habana, v. 146, n.1 - 2, jan/dez. 2011. p. 5 - 18.

SEGURA, Carmen Magaly León. "El municipio y los procesos de desarrollo local en Cuba". Revista Economía y Desarrollo, La Habana, V. 150, n. 2, jul-dic. 2013. 
VEGA, C. Sinaí Boffill; et al. “¿Cómo evaluar el desarrollo local en Cuba? Caso Yaguajay”. Revista Congreso Universidad. La Habana, v.1, n.1. 2012. p. 1 - 11.

VIANI, Marina Majoli. Ciencia y desarrollo em Cuba: aspectos del desarrollo científico y tecnológico cubano (1959-1999). 1999. Tese (Doutorado) - Curso de Departamento de Sociología., Universidade de La Habana, La Habana, 1999.

VIGO, Liset Hernandez. Convocatoria al Fórum de Ciencia y Técnica 2018. Disponível em: https://www.uclv.edu.cu/convocatoria-al-forum-ciencia-tecnica-2018/. Acesso em: 22 jun. 2019.

VILABOY, Sergio Guerra. Cuba a la mano: Anatomía de un país. Barranquilla: Editorial Universidad del Norte, 2015.

\section{A Universidade, o Fórum de Ciência e Técnica e o Desenvolvimento Local Sustentável em Cuba}

\section{Resumo}

Nesta contribuição sobre os 60 anos da Revolução Cubana, examina-se a contribuição da universidade (com sua ciência, tecnologia e inovação) e do Fórum de Ciência e Técnica para o "desenvolvimento local sustentável" cubano. Os dados aqui mobilizados resultam de entrevistas realizadas com profissionais cubanos, em julho de 2017, e também, de material bibliográfico obtido a partir dos contatos então estabelecidos. Verifica-se que a universidade cubana passou, ao longo dessas seis décadas, por importantes mudanças: a produção de conhecimento, antes preponderantemente voltada para o mercado, para a tecnologia de ponta e para a exportação, passou a ser orientada para a solução dos problemas concretos e básicos da população. Essa realidade se expressa nos exemplos exitosos da relação entre universidade e desenvolvimento local. As inovações se apoiam na (e promovem a investigação científica, facilitando os fluxos de conhecimento e a geração e disseminação de tecnologias alternativas. Neste contexto, ganha destaque a experiência do Fórum de Ciência e Técnica, uma especificidade do processo cubano de desenvolvimento científico e tecnológico. Ela indica a relevância da democratização da construção de novas tecnologias - que contrasta significativamente com as tecnologias convencionais capitalistas, assim mantendo acesa a chama dos ideais socialistas.

Palavras-chave: Ciência, Tecnologia e Inovação. Cuba. Desenvolvimento Local Sustentável. Fórum de Ciência e Técnica. Socialismo. Universidade.

\section{La Universidad, el Foro de Ciencia y Técnica y el Desarrollo local Sostenible en Cuba}

\section{Resumen}

En esta contribución sobre los 60 años de la Revolución Cubana, se examina la relevancia de la Universidad (con su ciencia, tecnología e innovación) y del Foro de Ciencia y Técnica al "desarrollo local sostenible" cubano. Los datos aquí movilizados resultan de entrevistas realizadas con profesionales cubanos, en julio de 2017, y también de material bibliográfico obtenido a partir de los contactos entonces establecidos. A lo largo de estas seis décadas, la Universidad cubana ha experimentado importantes cambios: la producción de conocimiento, antes orientada principalmente al mercado, a la tecnología de vanguardia y a la exportación, se ha orientado hacia la solución de los problemas concretos y básicos de la población. Esta realidad se expresa en los ejemplos exitosos de la relación entre la Universidad y el desarrollo local. Las innovaciones se basan en (y promueven) la investigación científica, facilitando los flujos de conocimiento y la generación y difusión de tecnologías alternativas. En este contexto, gana destaque la experiencia del Foro de Ciencia y Técnica, una especificidad del 
proceso cubano de desarrollo científico y tecnológico. Ella indica la importancia de la democratización de la construcción de nuevas tecnologias - que contrasta significativamente con las tecnologías convencionales capitalistas, manteniendo así encendida la llama de los ideales socialistas.

Palabras-clave: Ciencia, Tecnología e Innovación. Cuba. Desarrollo Local Sostenible. Foro de Ciencia y Técnica. Socialismo. Universidad

\title{
The University, the Science and Technology Forum and Sustainable Local Development in Cuba
}

\begin{abstract}
In this contribution concerning the 60th anniversary of the Cuban Revolution we examine the contribution of the university (with its science, technology and innovation) and the Forum of Science and Technology for the "sustainable local development" in Cuba. The data mobilized here result from interviews conducted with Cuban professionals, in July 2017, and also, from bibliographic material obtained from the contacts then established. The findings suggest that the Cuban university has undergone major changes in the course of these six decades: the production of knowledge, which was previously predominantly oriented to the market, the state-of-the-art technology and the export, has become oriented towards solving the concrete and basic problems of the population. This reality is expressed in the successful examples of the relationship between the University and local development. Innovations are based on (and promote) scientific research, facilitating the flow of knowledge and the generation and dissemination of alternative Technologies. In this context, the experience of the Science and Technology Forum, a specificity of the Cuban process of scientific and technological development, is highlighted. It indicates the importance of the democratization of the construction of new technologies - which contrasts significantly with conventional capitalist technologies, thus keeping the flame of socialist ideals alight.
\end{abstract}

Keywords: Cuba. Science, Technology and Innovation. Socialism. Sustainable Local Development. The Science and Technical Forum. University. 